\title{
The effect of combustion temperature to low-tar gas production using oxygen-enriched air
}

\author{
Dinh Quoc Viet ${ }^{1,4}$, Nguyen Van Vinh ${ }^{1}$, Nguyen Tien Cuong ${ }^{3}$, \\ Pham Hoang Luong ${ }^{2}$, Van Dinh Son Tho ${ }^{2 *}$ \\ ${ }^{1}$ School of Chemical Engineering \\ ${ }^{2}$ Vietnam Japan International Institute of Science for Technology \\ ${ }^{3}$ School of Heat Engineering and Refrigeration, Hanoi University of Science and Technology \\ ${ }^{4}$ Faculty of Chemistry, Quy Nhon University
}

Received 7 November 2016; Accepted for publication 28 August 2017

\begin{abstract}
Tar content in producer gas from biomass gasification is a serious problem for fuel gas utilization in downstream applications. This work presents the experimental studies of acacia woodchip gasification in a downdraft gasifier with two stages air supply. The effects of oxygen concentration in gasified agent on the temperature of gasifier, the syngas composition, the lower heating value and tar content in the producer gas are investigated. Results indicate that oxygenenriched air rate not only favors to reduce tar component but also improves the heating value of the producer gas. When increasing oxygen concentration from 21 vol.\% to $42 \mathrm{vol} \%$ in the gasified agent, the tar content of the producer gas decreases from $67.4 \mathrm{mg} / \mathrm{Nm}^{3}$ to $30 \mathrm{mg} / \mathrm{Nm}^{3}$, hydrogen concentration increases from 7.28 to $13.15 \mathrm{vol} \%$, CO concentration increases from 19.65 vol. $\%$ to 26.52 vol. $\%, \mathrm{CH}_{4}$ concentration increases from 1.4 to 3.3 vol. $\%$ and the low heating value increases from $4.45 \mathrm{MJ} / \mathrm{m}^{3}$ to $7.30 \mathrm{MJ} / \mathrm{m}^{3}$, respectively. On the other hand, the carbon conversion efficiency, gasification efficiency and gas yield of the gasifier are also presented in this approach.
\end{abstract}

Keywords. Downdraft gasification, acacia woodchip, tar content, oxygen-enriched air.

\section{INTRODUCTION}

Global climate change due to $\mathrm{CO}_{2}$ emissions is currently debated around the world. This issue have become a major concern and has encouraged the researchers to look for greener sources of energy as alternatives to replace the fossil fuels. Therefore, research activities on renewable energy sources has become more and more important. One of the renewable energy sources is biomass. Biomass can be converted into energy via thermo-chemical processes such as gasification, direct combustion, and pyrolysis. Among them, biomass gasification presents highly interesting possibilities for expanding the utilization of biomass. Biomass gasification is a thermal conversion process where solid fuel is converted into a combustible gas using gasifying agent such as air and steam. Producer gas from biomass gasification can be utilized in internal combustion engines or turbines as power generation, especially in remote areas with no electricity supply.

In gasification process, the main technical obstacle is the efficient elimination of tar from the product gas. Therefore, tar removal remains an important part of the development of advanced techniques. Several options are available for tar reduction such as using catalytic cracking, thermal catalytic, steam reforming which may be called as in-situ tar reduction and the other method is called post-gasification reduction [1]. According to Joujaruek et al. [2], using throttles downdraft gasifier with singles and double air supply position could reduce tar significantly from 114 to 43.2 $\mathrm{mg} / \mathrm{Nm}^{3}$, while S.C. Bhattacharya et al. have reported that tar content of the product gas was in the range $19-34 \mathrm{mg} / \mathrm{Nm}^{3}$ for charcoal gasifier coupled to a two-stage wood gasifier [3]. Gong Cheng et al. have studied the oxygen-enriched gasification of biomass micron fuel (BMF). When the oxygen concentration increased from $21 \%$ to $31.4 \%$ the yield of tar distribution decreased from $12.17 \%$ to $3.75 \%$ [4]. Cuong Van Huynh etl al. [5] have investigated the oxygen content in the enriched air. When $40 \%$ oxygen was used, hydrogen increases by $70 \%, 47 \%$ and $32 \%$ for pine, mapleoak and seed corn, while CO increases by $34 \%, 18$ 
$\%$ and $8.6 \%$. Overall, it was found that oxygen and steam gasification was most effective for feedstock with low nitrogen and moisture contents. The purpose of this study is to characterize the effects of oxygen-enriched air as the gasifying agent on the tar content as well as the composition of syngas including the main constituents in the producer gas from two-stage biomass downdraft gasifier.

\section{MATERIALS AND METHOD}

\subsection{Material}

In this approach, acacia woodchips from acacia woodchips factory that were collected from remote areas and then cut into small pieces with a size of length about 3-4 cm were dried for a period of 2-3 weeks and used for a downdraft gasifier. In the other hand, for the appproximation, ultimate analysis and heating value, the sample was kept in closed polyethylene bags to avoid contamination prior to carrying out the tests. The samples were milled to powder and sieved to a particle size less than $1 \mathrm{~mm}$ before carrying out the tests. The proximate analysis was used to determine the volatile matter, fixed carbon and ash content. Moisture content was determined using the ASTM E871 standard. The volatile matter was measured by following procedures described in ASTM standard E872. The heating value of the sample was measured using Parr 1266 Bomb Calorimeter followed standard ASTM 5865-04 [6, 9]. The component of material will determine low heating value and the effect on the calorific value of producer gas.

\subsection{System description}

This study is done by a pilot-scale downdraft gasifier with two-stage air supply. The gasifier operate at atmospheric pressure and can use pure air or oxygen-enriched air as the gasified agent. The gasification system approximately corresponds to $30-50 \mathrm{~kg} / \mathrm{hr}$ of raw material with an average heating value of $16 \mathrm{MJ} / \mathrm{kg}$. In the main reactor of the gasifier, eight thermocouples were installed at different heights along the gasifier to measure the temperature of the dry, pyrolysis, combustion and reduction zone. The experiments were tested on the two-stage gasifier by varying oxygen-enriched rate 21 vol. $\%, 26$ vol.\% and 42 vol.\% oxygen-enriched in $700 \mathrm{1} / \mathrm{min}$ of gasified medium flow. Oxygen (99.8\%, supplied by Cryotech Vietnam Joint Stock Company) from a liquefied oxygen tank was employed as the gasifying agent, while air was supplied by fan blower. Air flow was measured and controlled by using rotameter and oxygen was measured and controlled by using a pre-calibrated flow meter to produce blends of oxygen and air up to desired oxygen levels, then oxygen and air join together and then were added into the gasifier. In this approach, different oxygen concentrations were employed to investigate the effect of oxygen concentration on the temperature of combustion zone that influence to tar content in producer gas. The acacia woodchip feed quantity of $100 \mathrm{~kg}$ was added into the gasifier. After the steady operation was achieved, a sample of producer gas was collected and analyzed off-line compositions $\left(\mathrm{H}_{2}\right.$, $\left.\mathrm{O}_{2}, \mathrm{~N}_{2}, \mathrm{CO}, \mathrm{CO}_{2}, \mathrm{CH}_{4}\right)$ using a gas chromatograph (GC) with detector TCD. Tar measurement unit was condenser system. The container was rinsed with dichloromethane to remove tar from the wall of container and kept in an oven at $105{ }^{\circ} \mathrm{C}$ for about 3 to $4 \mathrm{~h}$ to evaporate the added liquid and water.

\section{RESULTS AND DISCUSSION}

The results of the appproximation, ultimate analysis and LHV of acacia wood are given in table 1. The proximate analysis showed that the acacia wood was comprised of $13.78 \mathrm{db} . \%$ of fixed carbon content, $85.92 \mathrm{db} . \%$ of volatile matter, $0.3 \mathrm{db} . \%$ of ash content and $6.02 \mathrm{db} . \%$ of moisture content. The low heating value of acacia woodchip was $19.02 \mathrm{MJ} / \mathrm{kg}$.

\subsection{The effect of oxygen enriched air on temperature profiles and tar content in producer gas}

It was observed that increasing oxygen-enriched air rate from $21 \mathrm{vol} . \%$ to $42 \mathrm{vol} . \%$, the temperature of combustion and reduction zone increase figure 2 . The averaged temperature of combustion zone rise from 697 to $1008{ }^{\circ} \mathrm{C}$ could reduce tar content in the producer gas from $67.4 \mathrm{mg} / \mathrm{Nm}^{3}$ to $30 \mathrm{mg} / \mathrm{Nm}^{3}$. This trend can be explained by the exothermic rate and exothermic intensity. When increasing oxygen content in gasifying agent from $21 \mathrm{vol} . \%$ to $42 \mathrm{vol} . \%$, reaction rate was accelerated remarkedly and more power was released to the surroundings than absorbed compared with lower oxygen-enriched rate due to less nitrogen absorbs heat. Furthermore, according to figure 1, oxygen-enriched air rate in the gasifying agent also has great effect on the gasification temperature along the gasifier.

When increasing oxygen concentration from 21 vol.\% to 42 vol.\% in the gasifying agent, the temperature of reduction zone and pyrolysis also gradually increased, the temperature of reduction zone increases from 447 to $700{ }^{\circ} \mathrm{C}$, while the 
temperature of pyrolysis zone increases from 138 to $369{ }^{\circ} \mathrm{C}$. This trend may be due to that combustion process or partial oxidation occurs remarkedly where oxygen was added to form carbon monoxide and carbon dioxide, which provides large heat for the subsequent gasification reactions in reduction zone and pyrolysis zone. Therefore, temperature profiles of reduction and pyrolysis zone also increased when increasing oxygen-enriched air rate in the gasifying agent.

Table 1: Proximate analysis and heating values of acacia woodchip

Characteristics acacia woodchip

\section{Proximate analysis}

Ash content (\%-dry basis)

Volatile matter (\%-dry basis)

Fixed carbon (\%-dry basis)

Moisture content (\%-air dry)

LHV (MJ/kg)

19.02

Table 2: Syngas composition, heating value and tar content at different oxygen concentrations

\begin{tabular}{cccc}
\hline Feedstock & \multicolumn{3}{c}{ acacia woodchip } \\
\hline Oxygen $($ vol.\%) & 21 & 26 & 42 \\
\hline $\mathrm{H}_{2}($ vol.\%) & 7.28 & 10.55 & 13.15 \\
$\mathrm{CO}($ vol.\%) & 19.65 & 24.56 & 26.52 \\
$\mathrm{CO}_{2}($ vol.\%) & 13.91 & 17.81 & 21.66 \\
$\mathrm{CH}_{4}($ vol.\%) & 1.39 & 2.62 & 3.29 \\
$\mathrm{~N}_{2}($ vol.\%) & 57.20 & 42.82 & 33.69 \\
$\mathrm{LHV}\left(\mathrm{MJ} / \mathrm{m}^{3}\right)$ & 4.45 & 6.23 & 7.30 \\
Tar content & 67.4 & 48 & 30 \\
$\left(\mathrm{mg} / \mathrm{Nm}^{3}\right)$ & & & \\
\hline
\end{tabular}

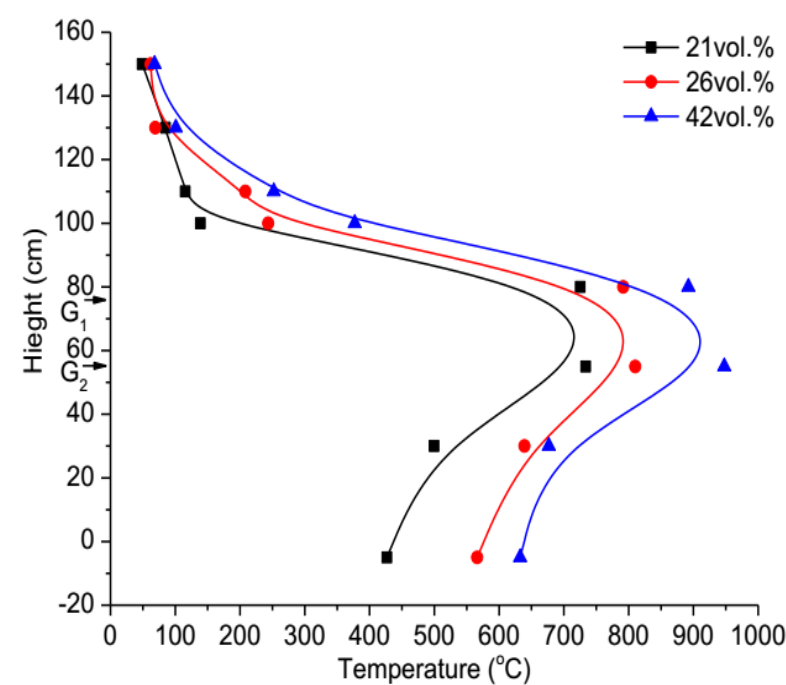

Figure 1: Temperature profiles along the gasifier

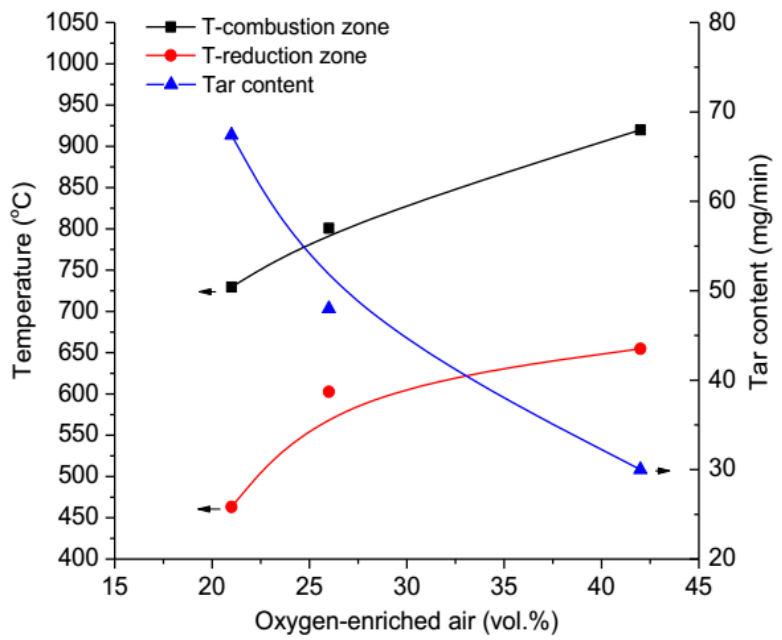

Figure 2: Tar contents as functions of temperature in the combustion zone

\subsection{The effect of oxygen enriched air on syngas composition}

The effect of oxygen-enriched air rate on the gas composition was showed figure 3 .

The hydrogen content in producer gas for acacia woodchip gasification increases from 7.28 and 13.15 vol.\%.

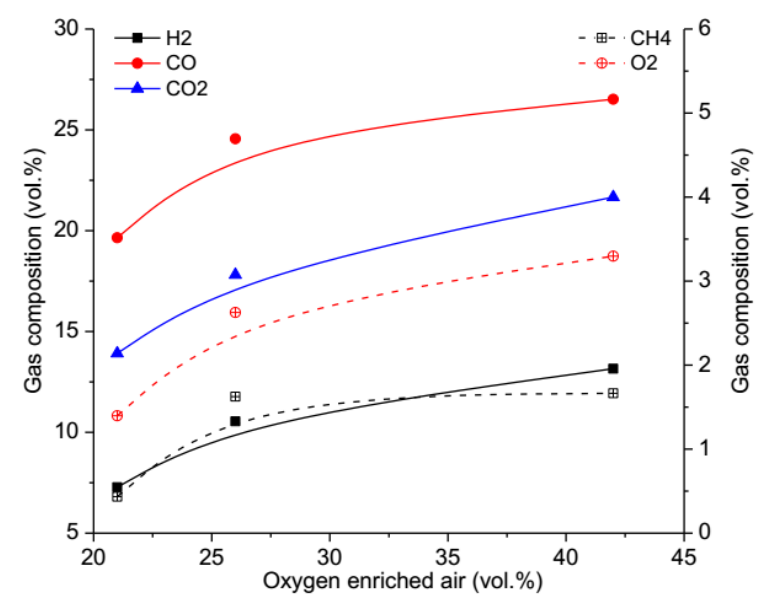

Figure 3: Effect of oxygen concentration on the producer gas composition

According to Zhou et al., [7] the temperature is one of the most important parameters for increasing hydrogen content of the syngas. Increasing temperature will favor the forward water-gas shift reaction and reforming reaction to release more $\mathrm{CO}$ and $\mathrm{H}_{2}$. Hydrogen is mainly formed from reaction (1) and reaction (2).

$$
\begin{aligned}
& \mathrm{CH}_{4}+\mathrm{H}_{2} \mathrm{O}=\mathrm{CO}+3 \mathrm{H}_{2}, \Delta \mathrm{H}=206 \mathrm{KJ} / \mathrm{kg} \\
& \mathrm{C}+\mathrm{H}_{2} \mathrm{O}=\mathrm{CO}+\mathrm{H}_{2}, \Delta \mathrm{H}=131.3 \mathrm{~kJ} / \mathrm{kg}
\end{aligned}
$$

According to previous studies [5,8], reaction (1) and (2) are the most favorable when gasification 
temperature is above $800{ }^{\circ} \mathrm{C}$ because higher temperature provides more energy endothermic reaction of steam (water or steam can be formed from the combustion of hydrogen and the moisture in biomass). The temperature of combustion zone of the tests are gradually increased to above $1008{ }^{\circ} \mathrm{C}$ (figure 2), so higher hydrogen concentration is improved when increasing oxygen-enriched air rate in the gasifier. The trend of higher hydrogen content is an agreement with the results of Cuong Van Huynh et al and Gong Cheng et al. [4, 5]. CO concentration in producer gas also increases when oxygen percentage increases from 21 to 42 vol.\%. The $\mathrm{CO}$ content in the syngas achieved from acacia woodchip increases from 19.65 to 26.52 vol.\%. When oxygen-enriched air is added into the gasifier, the concentration of $\mathrm{CO}$ increases because more oxygen volume is to enhance the oxidation reaction, partial oxidation reaction and even pyrolysis reaction and then releasing more heat to improve the gasification process. Moreover, $\mathrm{CO}$ component is mainly formed from reaction (1), (2) and reaction (3).

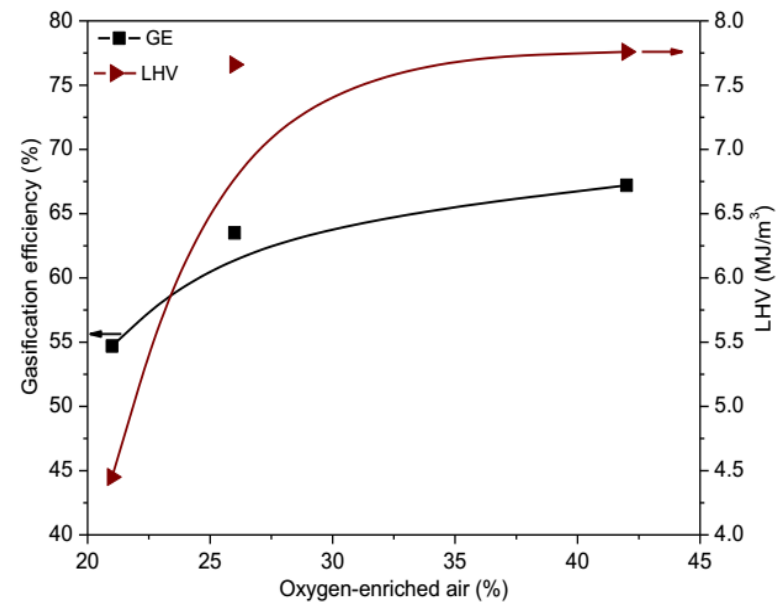

Figure 4: Effect of oxygen concentration on gasification efficiency and LHV

$$
\mathrm{C}+\mathrm{CO}_{2}=2 \mathrm{CO}, \Delta \mathrm{H}=172.6 \mathrm{~kJ} / \mathrm{mol}
$$

Higher temperature also improves the concentration of $\mathrm{CO}$ in reaction (3) which is an endothermic reaction. As shown in figure 4, the temperature of combustion and reduction zone increase with increasing oxygen-enriched air rate in the gasifying agent. Therefore, the decrease in the nitrogen dilution and higher temperature of combustion zone favor to increase $\mathrm{CO}$ content in producer gas by reaction (3). The trend of the increase of $\mathrm{CO}$ content is an agreement with the results of Gong Cheng et al. [4] for another material.

The effect of oxygen-enriched air rate on methane and carbon dioxide composition is also shown in figure 3 . It can be seen that the amount of $\mathrm{CO}_{2}$ content in the producer gas changes between 13.91 and 21.66 vol.\% for acacia woodchip when oxygen concentration in oxygen-enriched air increases from 21 vol. $\%$ to $42 \mathrm{vol} \%$. The decrease of $\mathrm{CO}_{2}$ content in the syngas is expected because more oxygen in the oxygen-enriched air is added into the gasifier will generate more and more $\mathrm{CO}_{2}$ but improve $\mathrm{CO}$ and enhance combustion reaction in the gasifier. The concentration of $\mathrm{CH}_{4}$ in the syngas is the lowest in producer gas of gasification process. figure 3 depicts that the amount of $\mathrm{CH}_{4}$ content slowly increases from 1.39 to 3.29 vol.\% when increasing oxygen concentration in oxygen-enriched air. The increase might be caused by reduced nitrogen content in the gasifying agent. This tendency is an agreement with the results of Cuong Van Huynh, Gong Cheng for another biomass $[4,5]$.

\subsection{Gasification efficiency, LHV, carbon conversion efficiency $\left(C_{\text {eff }}\right)$ and syngas yield $\left(G_{\mathbf{y}}\right)$}

The gasification efficiency and low heating value of acacia woodchip with oxygen-enriched air in the gasifier were shown in figure 4 . It can be seen that the increasing trend of LHV and gasification is similar. The LHV of the product gas strongly increased from 4.45 to $7.3 \mathrm{MJ} / \mathrm{m}^{3}$ when increasing oxygen concentration in oxygen-enriched air from 21 vol.\% to 42 vol.\%. The low heating value of the syngas is directly regarding the concentration of combustible gas composition such as $\mathrm{H}_{2}, \mathrm{CO}, \mathrm{CH}_{4}$.

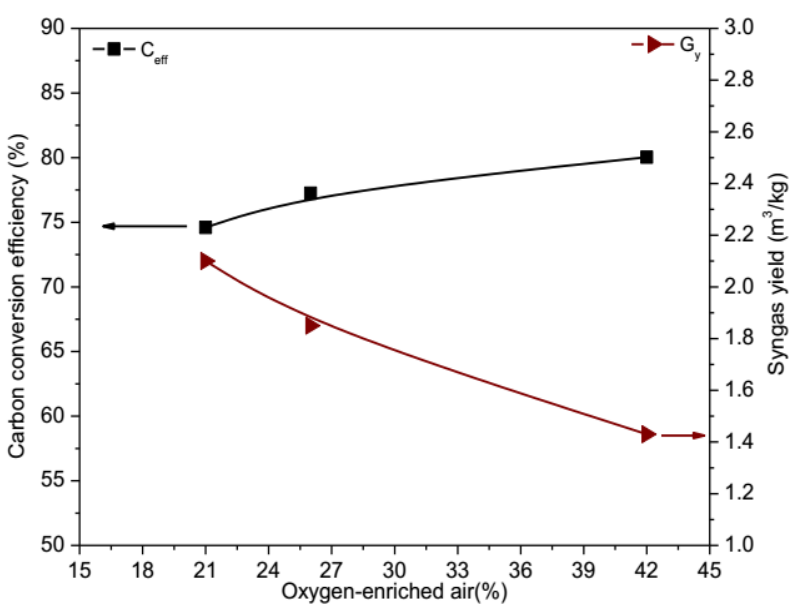

Figure 5: Effect of oxygen concentration on carbon conversion efficiency and the syngas yield

According to previous discussion figure 3 , the concentration of $\mathrm{CH}_{4}, \mathrm{CO}, \mathrm{H}_{2}$ remarkedly increased when increasing oxygen concentration and the decrease of nitrogen content in the gasifying agent. It is two main reasons to favor the increase of LHV 
of the syngas. Furthermore, gasification efficiency gradually increased with the increasing oxygen concentration in oxygen-enriched air. The increase might be explained by the fact that more tar was cracked into the fuel gas when combustion temperature increased from 697 to $1008{ }^{\circ} \mathrm{C}$ (previous discussion). This trend is an agreement with the results of Gong Cheng [4].

Syngas yield capacity is the most important parameter to evaluate the performance of the gasifier. Fig 5 depicts syngas yield $\left(\mathrm{G}_{\mathrm{y}}\right)$ and carbon conversion efficiency $\left(\mathrm{C}_{\text {eff }}\right)$ with varying oxygen concentration levels in the gasifying agent. The $\mathrm{G}_{\mathrm{y}}$ decreases from 2.1 to $1.43 \mathrm{Nm}^{3} / \mathrm{kg}$ (figure 5) when increasing oxygen concentration in the gasifying agent. However, the carbon conversion efficiency $\left(\mathrm{C}_{\text {eff }}\right)$ increases slightly from 74.6 to $80.04 \%$ (figure 5 ) whith increasing oxygen levels. The decrease of $\mathrm{G}_{\mathrm{y}}$ might be explained by reduced nitrogen content in the gasifying agent and the increase of $\mathrm{C}_{\text {eff }}$ caused by more tar was craked into the fuel gas when when increasing oxygen-enriched air rate in the gasifying agent. Hence, the introduction of oxygen-enriched air significantly improve the performance of gasification process and the quality of the syngas.

\section{CONCLUSION}

The effects of combustion temperature on the tar formation and the syngas composition using oxygenenriched air were studied experimentally in a pilot scale two-stage biomass gasification system with different oxygen-enriched air. In this study, the oxygen level in the gasifying agent was increased from 21 to $42 \mathrm{vol} . \%$. The experiments of several tests show that the oxygen levels have a strong influence on the tar formation and the syngas composition. When the oxygen concentration increased from 21 vol. $\%$ to 42 vol. $\%$, the low heating value increased from 4.45 to $7.3 \mathrm{MJ} / \mathrm{Nm}^{3}$, carbon conversion efficiency increased from 7.4 to $80.04 \%$, gasification efficiency increased from 54.7 to $67.2 \%$, temperature profiles of combustion zone increased from 687 to $1008{ }^{\circ} \mathrm{C}$, tar content reduced significantly from 67.4 to $30 \mathrm{mg} / \mathrm{Nm}^{3}$ (figure 2). Moreover, the concentration of the syngas composition along the gasifier also increased from combustion zone to reduction zone when higher oxygen concentration was used in the gasifer.
Hence, the introduction of oxygen-enriched air significantly improve the performance of gasification and the quality of the fuel gas.

Acknowledgements. This research was carried out with the financial support of the research collaboration between Hanoi University of Science and Technology and Gent University, Belgium: Research and application of Biomass gasification technology for electric/energy application of Vietnam remote areas, code ZEIN2013RIP021.

\section{REFERENCES}

1. P. Basu. Biomass Gasification and Pyrolysis Handbook, Elsevier (2010).

2. K. Jaojaruek, S. Jarungthammachote, M. K. B. Gratuito, H. Wongsuwan, and S. Homhual. Experimental study of wood downdraft gasification for an improved producer gas quality through an innovative two-stage air and premixed air/gas supply approach, Bioresour. Technol., 102(7), 4834-4840 (2011).

3. S. C. Bhattacharya, A. H. M. Mizanur Rahman Siddique, and H.-L. Pham. A study on wood gasification for low-tar gas production, Energy, 24(4), 285-296 (1999).

4. G. Cheng, P. wen He, B. Xiao, Z. quan Hu, S. ming Liu, L. guan Zhang, and L. Cai. Gasification of biomass micron fuel with oxygen-enriched air: Thermogravimetric analysis and gasification in a cyclone furnace, Energy, 43(1), 329-333 (2012).

5. C. Van Huynh and S. C. Kong. Performance characteristics of a pilot-scale biomass gasifier using oxygen-enriched air and steam, Fuel, 103, 987-996 (2013).

6. D. Q. Viet, N. Van Vinh, P. H. Luong, and V. D. S. Tho. Thermogravimetric Study on Rice, Corn and Sugar Cane Crop Residue, J. Sustain. Energy Environment, 6, 87-91 (2015).

7. J. Zhou, Q. Chen, H. Zhao, X. Cao, Q. Mei, Z. Luo, and K. Cen. Biomass-oxygen gasification in a hightemperature entrained-flow gasifier, Biotechnol. Adv., 27(5), 606-611 (2009).

8. P. M. Lv, Z. H. Xiong, J. Chang, C. Z. Wu, Y. Chen, and J. X. Zhu. An experimental study on biomass airsteam gasification in a fluidized bed, Bioresour. Technol., 95(1), 95-101 (2004).

9. D. Q. Viet, N. Van Vinh, and V. D. S. Tho. Thermogravimetric analysis and Kinetic study of acacia wood pyrolysis, Vietnam J. Chem., 53(6e4), 185-191 (2015).

\section{Corresponding author: Van Dinh Son Tho}

School of Chemical Engineering

Hanoi University of Science and Technology

No 1., Dai Co Viet Road, Hai Ba Trung Dist., Hanoi

E-mail: tho.vandinhson@ hust.edu.vn; Telephone: 0973604372. 
